\title{
Intelligent Fixture System for CNC Milling Machining of Thin-walled Structure
}

\author{
Zhijie Zhang, Jingyu Yang, Hailong Wang, Chen Li, Qing Wang, Jiahe Sun, Tianfen Mo and Shiwei Sun \\ Laboratory of Space Solar Power Station Dynamics and Control, Innovation Studio of Marine-Space Science \& Technology, \\ Faculty of Aerospace Engineering, Shenyang Aerospace University, Shenyang, China
}

\begin{abstract}
This paper mainly makes the analysis of the corresponding problems of Milling Thin-walled Structures in aerospace field with a digital control. The main contents are as follows: Firstly, on the basis of the present research, the processing characteristics of thin-walled parts under high-speed machining technology and the actual processing problems are summarized. Secondly, selecting the vertical milling process as the object of study, the elastic and elastic plastic deformation of the thin wall plate are analyzed in theory, and the finite element model is established to simulate the machining process. Thirdly, according to the existing research, the phenomenon of cutting chatter occurred in the processing of thin-walled parts and the problems caused by it are studied. Fourthly, in view of the above-mentioned problems of elastic-plastic deformation and flutter, a more effective solution is proposed and a new idea and basic design of the intelligent fixture system of thin-walled structure is proposed. Finally, using CATIA software, 3D solid modeling of this intelligent fixture is carried out.
\end{abstract}

Keywords-thin-walled parts; milling; high precision; machining deformation; finite element; $3 D$ modeling

\section{INTRODUCTION}

Although the thin-walled parts in the aviation industry has many advantages, the overall processing accuracy of thin-walled structural parts control problems, has been plagued by the aviation industry. At present, the manufacturing level of thin wall parts has become an important symbol to measure the level of aviation and aerospace technology in the world. So it is necessary to carry out the research on this kind of problem.

Both at home and abroad for the special fixture were studied, such as the use of hydraulic adjusting tool in machining parts, the outer contour when the cutting tool point automatic platen pressing close to get out of the way, the cutting tool plate immediately back in pressing parts. Some studies are presented based on an analysis of the dynamic response of a pocket using a plate model, which is described using the global and local optimization used to match the pocket structure[1]. In addition, there is a study in order to optimize the positioning of the thin walled workpiece in the milling, a precise finite element model is proposed. The thickness variation of workpiece in peripheral milling is considered. The positioner under the auxiliary positioning surface will change the surface error of the thin wall parts in milling[2].More in other studies, a new concept is introduced to simulate the dynamics of thin-walled structures in the process of machining by using a multi span plate with a torsional and translational spring. Develop and implement a complete constraint based formula to consider the effect of rigid fixture support[3].

\section{ANALYSIS OF PROCESS CHARACTERISTICS OF THIN WALL STRUCTURE}

\section{A. Influencing Factors of Machining Deformation of Thin} Wall Structure

Thin walled structure parts are widely used in aerospace industry, it is mainly composed of the side wall and web plate. The structure of the general shape of the general will be more complex, large size, large machining allowance, and low rigidity, processing technology is poor, very easy to produce deformation. And it has various forms, difficult to control, the above characteristics lead to the machining precision is difficult to obtain. The main factors affecting the machining precision are as follows.

Effects of parts of material and structure.

(2) The influence of cutting force and cutting heat

(3) The effect of residual stress

(4) The impact of clamping

(5) The influence of machine tool system flutter

Thin wall parts in the cutting process, with the decrease of the thickness of the parts, the rigidity of the parts is reduced, and the natural frequency is reduced. When the natural frequency of the workpiece is reduced to the frequency doubling component of the exciting force, the system flutter can be induced. Under the action of the exciting force, the workpiece will be deformed, the deformation has not been restored in time, the next knife will cut. At this time, due to the reduction of the cutting thickness, the friction between the tool and the workpiece can also cause the cutting chatter. And because the chatter is difficult to predict, the machining accuracy of the workpiece is very difficult to control.

\section{ANALYSIS OF STRESS AND DEFORMATION CHARACTERISTICS OF THIN WALL PARTS}

\section{A. Metal Cutting Deformation}

Metal cutting is to remove material from the workpiece by the tool, so that the shape, size, position and surface quality of the workpiece are in conformity with the technical requirements. From the theory of material mechanics, it is known that the material of the metal cutting layer is increased by the stress of the cutting tool, and the elastic deformation will occur. When 
the stress value reaches the elastic limit, it will produce plastic deformation, and the metal layer and the parent metal layer break up to form a cutting[4].

Cutting is the elastic deformation, plastic deformation and shear slip, which is caused by the extrusion of the cutting tool in front of the cutting tool. The cutting layer metal is separated from the parent material into the chip.

\section{B. "Cutter relieving" Phenomenon in the Milling of Thin Wall Parts}

In the machining process of thin wall parts, due to the action of cutting force, the workpiece has a certain elastic and elastic plastic deformation. This deformation is mainly due to the cutting force, cutting heat, loading and clamping force under the action of deflection caused by the surface deformation, and mainly caused by the cutting force. In the milling process workpiece due to the cutting force of the elastic plastic deformation, after cutting and elastic recovery, plastic deformation of partial recovery, resulting in less cut a portion of the material, the cutting amount of the actual parts is less than cutting requirements. At the same time, the actual surface position and the theoretical position of the thin wall are in error.

When using the end milling cutter to process the thin wall part, because the wall thickness is small, the rigidity difference, the action of the cutting force can produce the same as Figure 1 "Undercut" phenomenon

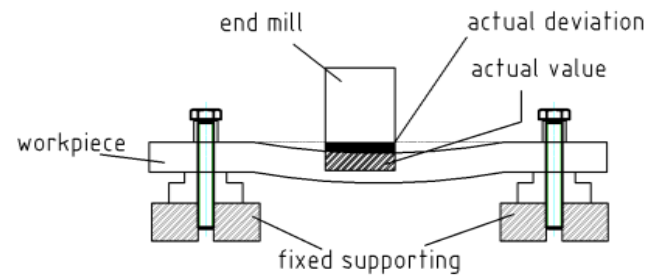

FIGURE I. "UNDERCUT"

\section{Finite Element Simulationmetal Cutting Deformation}

During the milling process of thin-walled parts, the cutting forces of periodic changes are acting on the thin wall parts dynamically. Thin wall structure stiffness in the thickness of the direction is very small, so in the thickness of the direction of deformation should also be much larger than the length and width of the deformation. Therefore, along the thickness direction of the machined component is the main factor to determine the workpiece surface error. We can ignore $\mathrm{X}, \mathrm{Y}$ direction of force influence on the deformation, and consider only the $\mathrm{Z}$ direction cutting force on thin wall parts in the vertical direction of deformation of the size of the effect. See Figure 2[5].

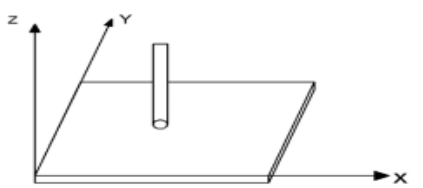

FIGURE II. COORDINATE DISTRIBUTION
Based on the above theoretical analysis, the CAE (Computer Aided Engineering) software is used to analyze and calculate the deformation of thin-walled parts in the milling process. The establishment of geometric and physical model as shown in Figure 3, Aluminum Alloy 2A12 selection of workpiece materials, the elastic modulus 280GPa, Poisson's ratio is 0.33 ; the applied load and boundary conditions; to divide grid parts. The calculated deformation results are shown in Figure 4.

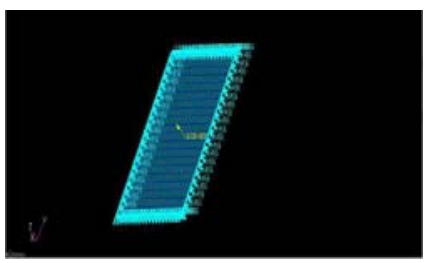

FIGURE III. MODEL

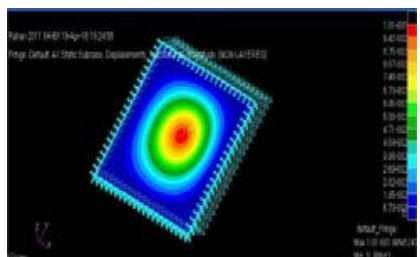

FIGURE IV. DEFORMATION RESULT

Subsequently in the workpiece unit we plus four $\mathrm{Z}$ direction of the constraint conditions (used to simulate the support) as shown in Figure 5. The calculated deformation results are shown in Figure 6.



FIGURE V. IMPOSE CONSTRAINTS

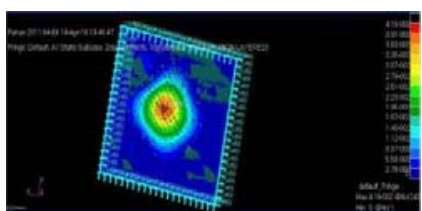

FIGURE VI. RESULTS

\section{DESIGN OF INTELLIGENT FIXTURE SYSTEM}

\section{A. The Core Principle of Fixture}

According to the above research, the main factors affecting the deformation of the workpiece is the component of cutting force in the thickness direction. Therefore, try to reduce the influence of the surface will greatly reduce the workpiece error. To sum up, the fixture should be provided to the support who apply support force on a surface that is opposite to the surface that is to be processed, thereby offset the cutting force in the thickness direction component. However, the thin-walled structures are complex, difficult to ensure that everywhere can arrange support. Considering the above, I design a support 
instead of multi support, let the support "follow the knife". This is the movable floating support as shown in Figure 7, which reaches the ideal state of the support below the tool.



FIGURE VII. MOVABLE FLOATING SUPPORT

In summary, the new fixture with fixed support as movable floating support. The fixed bearing is positioned around the workpiece for fixing the workpiece. These parts can be removed without affecting the accuracy of parts because of the fixed deformation. When the initial clamping, the two supporting functions of the fixed and floating are used to make the work force of the workpiece to be uniform, thereby preventing unnecessary initial residual stress, thereby reducing the clamping error and improving the processing precision.

\section{B. The Support Unit Translational Part Design}

The translation part is let support unit "follow" the tool to feed together. For this part, only need to keep up with the tool and overcome some friction resistance (the text will be introduced), you do not need to achieve the same high torque or high precision as machine tools. Therefore, this part is a Two axes linkage device that select double motor drive screw in guide rails as Figure 8. The advantages of this device is of simple structure, easy to control.

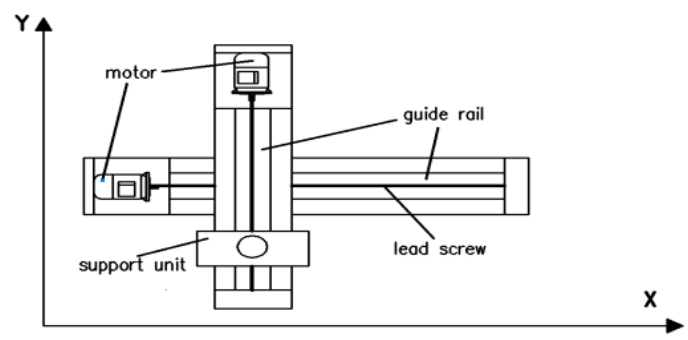

FIGURE VIII. TWO AXES LINKAGE DEVICE

Part material reference

C45E4, as the base of the overall structural material selection, with high strength and good machinability, after appropriate heat treatment can obtain a certain toughness, plasticity and wear resistance, convenient material source.

Motor with large torque stepper motor 86BYG250AN, high precision, simple control.

\section{Design of Support Unit Structure}

\section{1) Design of support structure in $Z$ direction}

Support structure in $\mathrm{Z}$ direction is to provide support force to offset tool pressure in the $\mathrm{Z}$ direction . Similar to the above two axis linkage, to retain the advantages of simple in structure and easy to operate, using the same motor driven screw, on the guide rail driving transmission contact unit, as shown in Figure 9 , in order to adjust the height and supporting.

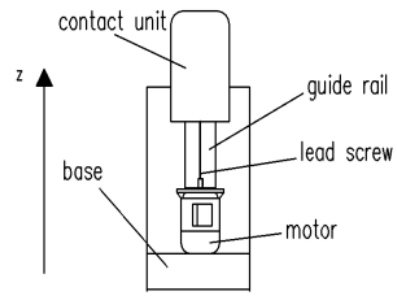

FIGURE IX. SUPPORT STRUCTURE IN Z DIRECTION

2) Design of external and internal vibration isolation of contact unit

Cutting chatter is a very violent vibration between the cutting tool and the workpiece. And a lot of influence factors, is a very complicated vibration phenomenon. Vibration of the tool with respect to the surface of the workpiece will cause vibration marks on the surface, directly affect the surface precision and roughness of the parts, and indirectly affect the performance of the parts. The vibration isolation design of contact element is particularly important.

Prior to the introduction of the internal structure, I first explain the part of the external contact with the workpiece. On the contact unit of the stress analysis, it is not difficult to find that in addition to the downward pressure on the workpiece, there is a horizontal direction of friction resistance. In order to reduce the resistance, I design the contact unit of the workpiece to contact the point of the ball, such as the Figure 10, so that the friction resistance can be greatly reduced.

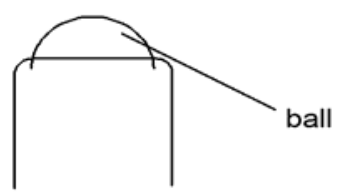

FIGURE X. EXTERNAL CONTACT UNIT DESIGN

The vibration isolator is composed of a mass free linear spring and a mass damper, as shown in Figure 11. Since then, according to the different machine tool system can adjust the parameters[6].

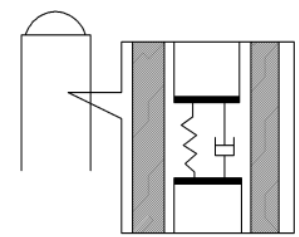

FIGURE XI. INTERNAL VIBRATION ISOLATION 


\section{Realization of Intelligent Fixture System}

The flow chart of control operation at thin-walled milling intelligent fixture system as shown in Figure 12. System consists of two parts: in the preparatory stage before the start of the cutting, a computer to obtain tool path and storage analysis, on the other hand, the displacement sensor that is placed below the workpiece obtain the initial position and records before processing. To start processing, two parts simultaneously: On one hand, computer according to the tool path drive axle transmission device whose supporting unit has been below the cutter are and follow the tool to move together. On the other hand ,sensors monitor the workpiece position, once change, computer control $\mathrm{Z}$ direction support structure, to achieve the effect of supporting.



FIGURE XII. .FLOWCHART

\section{E. Fixture General Structure Design}

The fixture consists of three parts: clamp base, translational structure, support unit. The combination of the two (support unit is fixed on the translational structure) is a supporting module. Each supporting module can be installed in the center of the fixture base in a free way. A fixed support for fixing the workpiece is provided around the base of the fixture. Taking three supporting modules as an example, the CATIA 3D model is established in Figure 13 and Figure 14, and the overall design of the fixture is completed

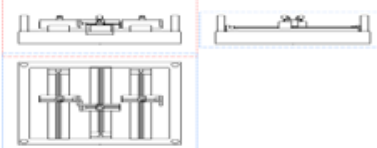

FIGURE XIII. THREE VIEWS

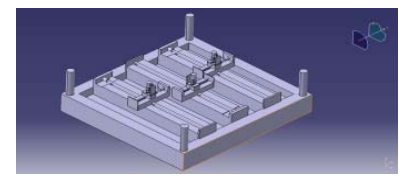

FIGURE XIV. 3D PLOT

\section{SUMMARY AND PROSPECT}

Intelligent fixture system for processing of thin-walled parts provides relatively better machining accuracy, reduce the rejection rate of the thin-walled parts, shorten the production cycle, provides new ideas for the future more advanced processing technology, with broad prospects for development.

\section{A. Summary of Research Work}

The main research results of this paper are as follows: Firstly, summary of the process characteristics of thin wall parts in high speed machining technology. Put forward the actual processing problems. The main factors that affect the machining accuracy are analyzed and summarized; Secondly, the stress state and strain state of the metal workpiece during the cutting process are described. The "cutter relieving" phenomenon is analyzed, and the finite element software is used to simulate the deformation; Thirdly, according to the various factors that affect the machining precision, the structure of the new fixture for the design of a new type of fixture and the reasons for the design of the system are designed. The overall design of fixture parts, materials, parameters, assembly and so on. ;Finally, using CATIA software, the three-dimensional solid modeling of the new fixture, showing the location of the various components of the device, intuitive and vividly illustrates the structural characteristics of the device.

\section{B. Follow-up Research Prospects}

There are still some deficiencies in this research work, which need to be further improved and perfected in the future research, mainly in the following aspects:. Firstly, the compatibility of the structure with variable and complicated structure is still not high, the future design of more perfect system structure to be compatible with more complex structure parts; Secondly, isolation design of the device is not perfect, still need to debug the machine according to the different system. For the adaptive system and the intelligent machine tool adjustment parameters to be discovered; Finally, the dynamic milling simulation of thin-walled structure can make the corresponding use of engineering software to obtain more system parameters directly.

\section{ACKNOWLEDGMENT}

This project is supported by innovation and entrepreneurship training program for college students "Health monitoring system design of attitude-structure vibration of in-orbit spacecraft” (Grant No. 201610143050) in Shenyang Aerospace University. And it is supported by National Natural Science Foundation of China (Grant No. 51605308) "Co-evolution of fractional order coupled structure vibration-attitude dynamic and control of spacecraft"; The Liaoning Province doctor Science Research Fund Project "Co-evolution of fractional order coupled structure vibration-attitude dynamic and control of China Space Station”(Grant No. 201601178) ; The Liaoning Province "13th Five Year Plan" Higher Education Research Fund Project "Teaching quality monitoring system and safeguard mechanism research on Aerospace engineering majors" (Grant No. GHZD160012); The Liaoning Province Department of Education Fund Project "Study of fractional order coupled structure vibration-attitude dynamic and control of spacecraft" (Grant No. L2015414);The Liaoning Province Department of Education Fund Project "Research and practice on specialty of aerospace engineering based on recognition for engineering education”(Grant No.030201619);“Exploration and Practice of 'Theory+ Interesting+ Research' Innovative Teaching Mode"(Grant No.YJS2014-11); "Research on Intelligent Integrated Control of Coupling between Space Solar Power 
Station Structure Vibration and Attitude Control (Grant No.13YB22)"; "Simulation and experimental platform design of virtual control of hypersonic aircrafts (Grant No.DX501312)";"'Emote operation, display and control of electromagnetic launcher(Grant No. X1610318)”; "Design and analysis of intelligent metamaterial cloaking structure system (Grant No. X1610317)”.

\section{REFERENCES}

[1] Meshreki, Mouhab ; Kövecses, József ; Attia, Helmi ; Tounsi, Nejah. Journal of Manufacturing Science and Engineering, Transactions of the ASME, v 130, n 3, p 0310111-03101112, June 2008; ISSN: 10871357; DOI: $10.1115 / 1.2927444$.

[2] Liu, Shaogang ; Zheng, L. ; Zhang, Z.H. ; Wen, D.H. International Journal of Advanced Manufacturing Technology, v 28, n 7-8, p 653-658, April2006;SSN:02683768,E-ISSN:14333015;DOI:10.1158/0008-5472. CAN-05-3712.

[3] Meshreki, Mouhab ; Attia, Helmi ; Kövecses, József.Advanced Materials Research, v 223, p 652-661, 2011, Modelling of Machining Operations; ISSN: 10226680; ISBN-13: 9783037850954; DOI: 10.4028/www.scientific.net/AMR.223.652.

[4] Jiang Jinsan, the application of [J].CAD/CAM ultra high speed machining in aerospace manufacturing and manufacturing industry information, 2004, (4): 10-20.

[5] Jiang Jinsan, the application of [J].CAD/CAM ultra high speed machining in aerospace manufacturing and manufacturing industry information, 2004, (4): 40-54.

[6] Mechanical vibration solid mechanics teaching and research group, Department of engineering mechanics, Tsinghua University press $1980.850-62$ 